The operation was begun at 11.30 A.M.; by 1.45 the patient was conscious, and had recovered his hearing and speech; he asked who had operated and when told immediately said, " oh, I remember him," and gave a very good reason. The wound healed by first intention, and with the exception of some vagaries in temperature the recovery was uninterrupted. His own account of the injury was that he travelled from London with a friend (?) on June 21st, 1921, and left the train some 30 miles from where he intended to go; his friend discovered that he had friends in the neighbourhood and proposed to go to them. Both being tired by the journey from London and the summer night being fine and warm, they decided to sleep in the open. The next thing he remembered was waking up in hospital minus $£ 18$.

The man is now quite normal as regards speech, hearing, and memory.

\section{SPONTANEOUS RENAL FISTULA.}

By E. F. GUY, M.B., B.S. Lond., B.Sc. Wales. JUNIOR MEDICAL OFFICER, GRANGETHORPE HOSPITAL, MANCHESTER.

Spontaneous renal fistula is a rare occurrence, and the following case in a pensioner is of interest.

$\mathrm{J}$. B., aged 23, was admitted to Grangethorpe Hospital on Nov. 8th, 1920, with a discharging sinus in the right loin. He stated that during physical training in August, 1918, he was jumping from a board and slipped; in falling, the right side of his back was struck by a support. The acciden was followed by severe pain in the right loin, which almost prevented his walking, and kept him awake at night. Three weeks later a swelling formed in this region. He had slight pain on micturition, but the urine was clear and contained no blood. An abscess apparently formed under the skin and he was admitted to hospital. The abscess was opened without anæsthesia and a quantity of pus evacuated. Although scraped in December, 1918, the abscess failed to heal, and an operation was performed in April, 1919, the nature of which is not known. An X ray taken shortly after admission to this hospital showed indefinite shadows on the right side at level of the eleventh and twelfth ribs, the right side at level of the eleventh and twelfth ribs, nearer the iliac crest, thought to be calcified glands. Patient had no urinary symptoms or any kind.

First Operation.-On Feb. 10th, 1921, the sinus was explored and found to pass deep to the twelfth rib, part of which was excised. No sequestra were found. After this operation he had scalding at the end of micturition and a little pus in the urine for about a week. The urine was examined for tubercle bacilli but none found. The sinus remained open and further exploration was decided on.

Second Operation.-On June 30th the sinus was followed down, the operation necessitating removal of remainder of the twelfth rib. It was found to pass towards the upper pole of the right kidney with which it communicated. With a probe renal calculi were felt at the bottom of the sinus ; three calculi were removed. There was no hæmaturia after this operation and no obvious escape of urine from the sinus. As the sinus still failed to heal, a further $X$ ray was taken, which showed a shadow in the right kidney.

Third Operation.-On Sept. 4th the kidney was exposed by an oblique lumbar incision. It was felt to be rery sclerotic and adherent to surrounding tissues and to the diaphragm. The capsule could not be stripped. One large and two small calculi, apnarently encysted in fibrous tissue, were removed and the wound closed around gauze plugging. Following the operation, the urine contained a trace of albumin, but no blood, and again there was apparently no escape of urine from the wound. The sinus now slowly closed up and two months later was dry and soundly closed

Remarks.-This case agrees with those previously described as to absence of renal and urinary symptoms, and this fact, together with absence of blood from the urine after operation, and of any trace of urine in the discharge from the wound, is probably connected with the encysted condition of the calculi. At no time was there any suggestion of renal colic.

The three operations described were performed by Mr. Geoffrey Jefferson, to whom I am indebted for permission to publish these notes.

LITERARY INTELLIGENCE.-Mr. Murray announces the forthcoming, publication of "The Chemistry of the Radio-Elements," by Dr. A. S. Russell, and of a second revised) edition of "Cancer of the Breast and its 'Treatment," by Mr. W. Sampson Handley.

\section{Ittedical Sucreties.}

\section{ROYAL SOCIETY OF MEDICINE.}

\section{SECTION OF MEDICINE.}

The Diagnosis of Gastric Ulcer.

A MEETING of this section of the Royal Society of Medicine was held on Jan. 24th, Sir W. HALE-WHITF, the President, being in the chair.

Dr. C. BoLToN opened a discussion on the above. subject. After a brief description, illustrated by lantern-slides, of the various types of acute and chronic gastric ulcer, he passed to the means of recognition of the presence of an ulcer by (1) the accidents of the disease : hæmorrhage and perforation, the latter being outside the scope of the present discussion; (2) the associated disorders of gastric function; (3) $\mathrm{X}$ rays combined with a bismuth meal. Hoemorrhage.

Hæmorrhage constituted the most valuable diagnostic sign. The hæmorrhage from acute ulcer usually occurred without any preliminary gastric symptoms, and might take the form of hæmatemesis or melæna. In the latter case the patient not infrequently sought advice on account of fainting attacks or anæmia. The hæmorrhage might be mistaken for the bleeding consequent on certain nongastric diseases-hepatic cirrhosis, anæmias, \&c. There was also a form of gastritis which gave rise to hæmorrhage. Hæmorrhage from chronic ulcer was usually accompanied by a characteristic pain, and when it occurred might be said to clinch the diagnosis. Very occasionally chronic ulcers gave rise to melæna without symptoms, and such cases were very difficult to diagnose from cancer.

\section{The Interpretation of Disorders of Function.}

These might be motor or secretory ; chronic ulcer, by increasing the muscular irritability of the stomach gave rise to pyloric spasm with diminished rate of emptying, or occasionally to spasm in other parts of the stomach. Acute ulcer had no such effect unless situated close to one of the orifices. Such motor disorders were recognised by the symptoms of pain, and by means of the $X$ rays. Pain, of course, occurred in disorders of the stomach other than gastric ulcer, but the pain of gastric ulcer had usually the following very definite characteristics: it was situated in the epigastric region, and accompanied by tenderness and muscular rigidity ; it was severe and recurred frequently in more or less prolonged attacks it had a constant relation to the taking of food and was relieved by vomiting; and its characters appeared fairly constant in the same ndividual.

The alterations which occurred in the secretory function in gastric ulcer might occur in other gastric conditions, so that the results of a test-meal could only be of value when interpreted in conjunction with the other findings. The single test-meal giving the total free and combined $\mathrm{HCl}$ was open to the objection that the gastric contents varied constantly, while the interpretation of the curves obtained by the fractional method had not yet been fully worked out. Rehfuss regarded the curves of free $\mathrm{HCl}$ and of total acidity as being secretory curves, and that type which rises to a higher level than normal, such as is commonly found in pyloric ulcer, as a hyper-secretory curve. With Dr. G. W. Goodhart Dr. Bolton had done some experiments on this subject, and they had formed the conclusion that the curve of total chlorides. more nearly represented the secretory curve, since the $\mathrm{HCl}$ curve was affected by regurgitation of alkaline: duodenal contents when the pylorus was relaxed: They therefore regarded the climbing type of $\mathrm{HCl}$ curve, called by Rehfuss "the hyper-secretory curve," to be due to hypertonus or spasm of pylorus.

In general, the finding of an excess of total HCT after a single test-meal, or of the climbing type of acidity curve by the fractional method, were in 